\title{
Unidade e diferença: os Ye'kwana e suas relações com a fronteira binacional
}

Unity and difference. The Ye'kwana and their relation to the binational border

\section{Karenina Vieira Andrade}

\section{(2) OpenEdition \\ 1 Journals}

Edição electrónica

URL: http://journals.openedition.org/aa/3170

DOI: $10.4000 /$ aa. 3170

ISSN: 2357-738X

Editora

Programa de Pós-Graduação em Antropologia Social (UnB)

\section{Edição impressa}

Data de publição: 1 dezembro 2018

Paginação: 55-79

ISSN: 0102-4302

\section{Refêrencia eletrónica}

Karenina Vieira Andrade, «Unidade e diferença: os Ye'kwana e suas relações com a fronteira binacional», Anuário Antropológico [Online], v.43 n.2 | 2018, posto online no dia 26 maio 2019, consultado o 27 abril 2021. URL: http://journals.openedition.org/aa/3170 ; DOI: https://doi.org/ 10.4000/aa. 3170

\section{(c) (i) (9)}

Anuário Antropológico is licensed under a Creative Commons Atribuição-Uso Não-Comercial-Proibição de realização de Obras Derivadas 4.0 International. 


\title{
Unidade e diferença: os Ye'kwana e suas relações com a fronteira binacional
}

\author{
Karenina Vieira Andrade
}

UFMG

\section{Introduzindo o debate}

$\mathrm{Na}$ história da Antropologia Social (refiro-me não apenas à clássica tradição britânica de antropologia que se consolidou durante a primeira metade do século XX e teve como um de seus grandes pilares a obra de Radcliffe-Brown, mas a certo modo de se fazer antropologia que é diretamente tributário da influência de Émile Durkheim e de algumas de suas ideias), um dos temas que gerou intensos debates teóricos e formulações conceituais, à luz de estudos etnográficos em diferentes regiões do mundo, foi a discussão sobre a constituição das unidades sociológicas mais amplas com as quais operam os antropólogos e a natureza da força que mantém a coesão no interior de tais unidades, gerando o sentimento de pertença que faz com que os indivíduos se reconheçam como partes de um mesmo todo - em outras palavras, como membros de um mesmo grupo. O tema, de fato, parecia fascinar muitos antropólogos sociais da primeira metade do século XX que desenvolveram suas pesquisas de campo entre as ainda então chamadas "sociedades primitivas" ou "tribais", notadamente no continente africano. Uma miríade de etnografias produzidas neste período não só se dedicou ao exame da chamada dimensão da "Organização Social" (e do Parentesco), mas, precisamente, à busca por responder à seguinte indagação: em sociedades cuja estrutura social passa ao largo das formas de centralização política típicas dos Estados, onde reside a fonte de manutenção da solidariedade social e da coesão do grupo? Em outros termos, a questão de fundo que emergia aqui era a seguinte: no caso dos povos "sem Estado e sem leis", o que faz do grupo (ou deste grupo em particular), um grupo? Nesta tradição teórica, o parentesco, a religião e o compartilhamento de um mesmo território, por exemplo, eram dimensões da vida classicamente apontadas como aquelas que faziam as vezes do Estado enquanto fontes primordiais de onde emanavam o sentimento de coesão e unicidade.

Não é minha intenção examinar a fundo os desdobramentos deste debate no interior de parte da produção antropológica, ${ }^{1}$ mas apenas chamar atenção para alguns de seus ecos, à guisa de introdução, num outro contexto, mais recente, em torno do tema. Refiro-me, particularmente, ao contexto sul-americano no qual, 
findos os processos de colonização e com a emergência de Estados Nacionais independentes, passa-se a discutir em que medida haveria (se é que há) uma inflexão do estabelecimento de fronteiras internacionais no interior mesmo de certas unidades (aquelas constituídas pelos povos indígenas que resistiram ao processo de colonização e continuam a se reconhecer como unidades distintas em relação às sociedades nacionais não-indígenas), fronteiras estas que passaram a dividir seus territórios tradicionais (e, consequentemente, sua população) em porções situadas em diferentes países. Poderíamos continuar falando em um mesmo povo, sociedade ou grupo, no singular, cujas comunidades estão situadas em diferentes países? O estabelecimento de relações com diferentes Estados, com suas lógicas, constituições e políticas públicas singulares, se faria sentir no que tange ao sentimento de pertença a um mesmo todo, no caso dos povos que vivem nas fronteiras internacionais? Deixaria o grupo, num tal contexto, de ser um grupo?

Espero, ao final do texto, convencer o leitor de que esta é, em si mesma, uma falsa questão, uma vez que seu problema reside, justamente, na definição e uso de certos conceitos (sejam eles o de sociedade, grupo, povo ou etnia) que carregam um forte ranço da projeção de uma lógica própria da constituição das formações de tipo Estado-Nação. Operar com tal questão implica pressupor que as unidades sociológicas com as quais operamos são sempre, e a priori, dotadas de uma coesão interna que somente pode se manter face à homogeneidade que deve resultar do trabalho interno de solapamento da diferença, de modo que a incorporação de distintos elementos oriundos da interação (e das trocas) cotidiana com Estados Nacionais particulares levaria, inevitavelmente, à implosão do sentimento de se pertencer a um mesmo todo. Parte do problema, como se discutirá a seguir, deve-se não só a certa maneira de se definir o que são (e como se constituem, quais são seus limites) as tais unidades sociológicas com as quais nós, antropólogos, operamos, mas também a como elas se estabilizam e se perpetuam no tempo e no espaço. Com relação ao primeiro aspecto, a crítica não é nova; ela nos remete ao clássico "Sistemas Políticos da Alta Birmânia” de Leach, que já em 1954 dirigia uma crítica aos seus pares (justamente no contexto da Antropologia Social britânica de matriz durkheimiana) no que se refere à certa equação segundo a qual a unidade sociológica que circunscreveria os limites de uma pesquisa etnográfica se constituiria, em última instância, pela equação: um povo (uma sociedade, uma estrutura social) = uma mesma língua e uma mesma cultura. E mais: Leach chama atenção para a necessidade imperativa de trazer à tona um outro aspecto que diz respeito ao tipo de material com o qual 
os antropólogos operam na elaboração teórica: o fato de que lidamos, boa parte do tempo, com modelos (nativos). Com relação ao segundo aspecto mencionado (aquele que diz respeito à estabilização e perpetuação das unidades pretensamente homogêneas), tampouco há aqui novidade; lembremos o exaustivamente citado mote lévi-straussiano da "abertura para o outro" como uma das marcas distintivas de uma epistemologia “ameríndia” (Lévi-Strauss, 1993), cujo regime de relação com a alteridade seria marcado menos por um solapamento da diferença em seu interior e mais por uma abertura para sua incorporação criativa, em contraste com a epistemologia “ocidental”, ${ }^{2}$ que não suportaria a heterogeneidade em seu interior, apropriando-se de ideias, valores e invenções dos Outros de modo a "apagar" sua origem, como nos mostra Jack Goody no seu sagaz "O Roubo da História”. Ademais, a própria ideia de estabilização dos regimes de diferenciação seria fruto da ideologia subjacente ao modelo nativo "ocidental”, projetada em outros contextos estudados pelos antropólogos (vide a obsessão dos britânicos da primeira metade do século XX com a ideia de equilíbrio social, igualmente criticada por Leach). Se tais questões não são novas, espero que o contexto etnográfico que aqui apresento possa, em alguma medida, oferecer contribuições ao debate a partir do modo ye'kwana de estabelecer um regime de incorporação da diferença no qual a "mistura” não conduz à homogeneidade produzida a partir de sua negação ou solapamento.

\section{Quem são os Ye'kwana?}

Começo a responder a esta pergunta da maneira mais usual num texto etnográfico - onde estão, quantos são e como vivem os Ye'kwana, a unidade ${ }^{3}$ sociológica com a qual tenho trabalhado no desenvolvimento de pesquisa etnográfica ao longo da última década. Na Venezuela, as cerca de 60 aldeias ye'kwana estão situadas em amplo território nos estados Bolívar e Amazonas e cortadas pelos Rios Orenoco, Ventuari, Padamo, Caura, Paragua, Cuntinamo e Erebato. De acordo com o censo de 2011 do Instituto Nacional de Estatística (INE), a população total é cerca de 8.000 pessoas. No Brasil, são quatro aldeias ye'kwana situadas na porção noroeste do estado de Roraima, na Terra Indígena Yanomami, três delas ao longo do Rio Auaris (Tajädedatonnha, conhecida pelos não indígenas como Pedra Branca; Fuduwaadunnha, conhecida como Auaris e Kudaatannha, conhecida como Tucuxim) e uma situada ao longo do Rio Uraricoera (Waichannha, conhecida como Waikás). A população das quatro aldeias, de acordo com o censo de 2015, elaborado pela Secretaria Especial de Saúde Indígena (SESAI), é de 593 pessoas. Minha pesquisa 
iniciou-se em 2005 em Fuduwaadunnha, a maior das aldeias ye'kwana do lado brasileiro da fronteira, onde concentrei a quase totalidade do período de campo de 14 meses que deu origem à minha tese de doutorado (Andrade, 2007), tendo feito duas visitas a Tajädedatonnha, onde então vivia apenas uma família extensa com menos de uma dezena de moradores. Kudaatannha foi fundada durante o período em que vivi em Fuduwaadunnha e tive a oportunidade de acompanhar a expedição que escolheu o sítio onde seria situada a nova comunidade (Andrade, 2010, 2013). A maioria das famílias, que hoje vive lá, oriundas de Fuduwaadunnha, mudou-se definitivamente em 2008. Nos últimos anos, tenho desenvolvido pesquisa também em Waichannha, no Rio Uraricoera, além prosseguir trabalhando em Fuduwaadunha e Kudaatannha. Os dados etnográficos apresentados neste artigo são fruto, portanto, de pesquisa realizada nas quatro comunidades ye'kwana no lado brasileiro da fronteira, mas tive, ao longo dos anos, a oportunidade de trabalhar também com visitantes oriundos de comunidades do lado venezuelano da fronteira, bem como acompanhar a mudança definitiva de algumas famílias para as aldeias do lado brasileiro, como veremos a seguir.

Os Ye'kwana são falantes de uma língua Caribe e vivem em extenso território cortado pela fronteira internacional Brasil-Venezuela. Na literatura colonial, há registros de contato pelo menos desde o século XVIII (Barandiarán, 1991; Guss, 1990; Monterrey, 2015). Reconhecidos como exímios construtores e usuários de canoas, há muito faziam parte de uma densa e extensa rede de comércio com diversos outros povos da região, na qual inseriram os não-indígenas mais tarde, através de longas viagens fluviais que empreendiam às cidades coloniais e que permaneceram registradas na tradição oral. Na literatura histórica (documentos coloniais, relatos de cronistas, viajantes, missionários), há uma profusão de etnônimos utilizados para se referir aos Ye'kwana. Monterrey (2015) nos fornece uma longa lista de alguns destes etnônimos, seguida de sete razões que teriam levado ao uso de nomes distintos para se referir aos Ye'kwana: 1. OsYe'kwana viajavam muito, dada sua verve de grandes comerciantes; 2. Os cronistas não os perceberam como uma unidade; 3. Os nomes faziam referência a áreas geográficas específicas, na Venezuela, por exemplo, foram chamados durante muito tempo de Makiritare, já no Brasil, de Maiongong (Ramos, 1980) (o que, acrescento, está relacionado aos "outros" com os quais os não-indígenas travaram contato antes do que com os próprios Ye’kwana) e cada um destes "outros" atribuía-lhes nomes distintos, muitas vezes termos traduzíveis nas suas próprias línguas, a exemplo do termo Maiongong, que teria origem na língua 
Macuxi e significaria literalmente “cabeça redonda”, referindo-se ao corte de cabelo em formato de "cuia”, tradicionalmente usado por homens e mulheres ye'kwana; 4. Antropólogos, viajantes e moradores regionais teriam dado, em alguns casos, o mesmo nome para grupos distintos; 5 . Da mesma maneira, um mesmo grupo teria ganhado nomes distintos; 6 . Etnônimos refletiriam processos de contato, denominação e integração de outros povos. Os etnônimos podem "identificar diferenças internas e existência de subgrupos entre os ye'kwana e os povos por eles assimilados"; 7. Povos assimilados sob um mesmo nome podem, na verdade, tratar-se de grupos distintos. Como examinaremos mais detidamente a seguir, a autora interpreta a adoção do etnônimo Ye'kwana, tanto pelos próprios indivíduos que assim se identificam quanto pela literatura etnográfica, como um dos elementos, dentre outros, que indicam um processo de amalgamento de uma identidade étnica forjada a partir da incorporação de diversos grupos distintos. Monterrey se debruça sobre a história da região e suas redes de relações interétnicas de modo a analisar o que considera um aspecto negligenciado pela literatura etnográfica sobre os Ye'kwana. Seria justamente a variedade interna do grupo que teria permanecido oculta sob o etnônimo que ganhou força a partir do século XX, em um contexto político que deu lugar à produção de uma espécie de "identidade monolítica” ye'kwana. Examinaremos mais detidamente a tese da autora de modo a poder melhor investigar os elementos implicados na produção desta “identidade ye'kwana”, para que possamos, posteriormente, desenvolver algumas hipóteses acerca da relação destes com a questão das fronteiras internacionais levantadas no início deste artigo.

Há na literatura etnográfica um intenso debate sobre a profusão onomástica nas terras baixas amazônicas. ${ }^{4}$ Com relação à miríade de termos usados para se referir aos Ye'kwana, eu começaria destacando os pontos 1, 2, 3, 4 e 5 elencados por Monterrey e reproduzidos no parágrafo anterior. Parece-me importante apontar para um denominador comum aos cinco pontos, que são, em alguma medida, resultado, de um lado, da ignorância de cronistas, viajantes, missionários, que, a partir de contatos muitas vezes pontuais, sem um domínio mínimo da língua de seus interlocutores, marcados por interesses específicos, sejam comerciais, colonizadores, de conversão ou simples curiosidade colecionista (no que se refere à boa parte das fontes históricas) e, de outro lado, de certas inclinações teóricas (no que se refere à produção etnográfica) tais como aquelas criticadas por Leach (1954), mencionadas no início deste trabalho. Como afirmou Erikson (2011), os etnônimos na literatura parecem variar ao sabor de razões “ora ideológicas, ora fonológicas”. Entretanto, o 
autor nos faz um alerta acerca das críticas ao uso 'equivocado' pela literatura que me parece relevante (incluindo mesmo a crítica que aqui acabo de fazer):

Tudo acontece como se os títulos que figuram sobre as capas das monografias etnológicas relevassem (sic) mais frequentemente de aflitivos quiprocós semânticos, que nos ensinam mais sobre a personalidade dos autores que sobre as pessoas que se esforçam para descrever. Como se os etnônimos, até aqui, não tivessem tipicamente sido mais que a designação errada, disposta em meio a termos insultantes emprestados de vizinhos malvados, de um conjunto de pessoas amalgamadas em conjuntos frouxos, de contornos apressadamente definidos por pesquisadores tão ingenuamente abertos aos discursos maliciosos de seus guias, como ferozmente agarrados a suas inclinações essencialistas. Como se a chalaça xenofóbica de uns (os vizinhos mediadores) fosse conjugada à angústia taxonômica de outros (pesquisadores, missionários, agentes governamentais) para criar entidades fictícias, com denominações falaciosas e discriminatórias. (...) não vamos, de qualquer forma, jogar fora o bebê junto com a água do banho. Se as antigas designações deixavam a desejar, as novas não se tornam por isso, sistematicamente, pertinentes. (Erikson, 2011: 7-8).

Erikson ressalta ainda que o uso das "novas" designações, em alguns casos frutos de processos de incorporação por parte do próprio grupo de etnônimos, outrora atribuídos a eles por outrem, tem menos a ver com seus princípios de organização tradicionais e mais a ver com a política exterior do grupo. Este parece ser justamente o aspecto destacado por Monterrey ao apontar para o uso do etnônimo pelos próprios Ye'kwana, a partir do século XX, como estratégia política de produção de uma unidade étnica minoritária no contexto de um Estado Nacional, de modo a legitimar suas demandas por reconhecimento de direitos e assegurar sua sobrevivência enquanto grupo diferenciado. Embora eu não discorde da autora sobre um certo jogo que parece alternar momentos de fissão e fusão (voltarei a este ponto adiante), com a incorporação de “outros grupos” por parte dos ye'kwana, minhas conclusões são um tanto distintas, sobretudo a partir dos conceitos que mobilizo para dar conta da maneira como a diferença é manejada pelos ye'kwana enquanto matéria-prima da produção de um certo mundo e, em última instância, a produção de um regime de relação com a alteridade. Assim, interessa-me aqui debater precisamente o que significa ser Ye'kwana em termos daquilo que Erikson chama de "princípios de organização tradicionais”, mas (e aqui talvez destoando um pouco do autor) não porque estejam estes princípios apartados das relações políticas do 
grupo com seus Outros. Acredito que a separação entre um discurso produzido 'para fora' e um discurso produzido 'para dentro' é mais nossa e menos dos nossos interlocutores, não só porque ‘fora' e 'dentro' são posições relacionais, mas porque estão intimamente conectadas. Espero demonstrar que os princípios que ordenam o mundo propriamente ye'kwana continuam operando na produção de discursos e de um regime de relação com os Outros, ainda que devidamente infletidos pelo contexto político no qual se dão tais relações. Veremos como tanto no contexto da produção do semelhante (o mundo ye'kwana) quanto no contexto da relação com a alteridade (os não-ye'kwana) estamos diante de um gradiente de proximidade e distância muito mais complexo e refinado do que de polos estanques, marcados por uma pretensa homogeneidade interna, que se contrapõem. ${ }^{5}$

\section{Weichö: a diferença originária}

Debruço-me sobre as narrativas wätunnä ${ }^{6}$ para buscar compreender alguns dos princípios do modelo ye'kwana de operar com a diferença e, assim, melhor traduzir a afirmação corrente entre eles de que "somos todos misturados". Inúmeras vezes ouvi de homens mais velhos, e sobretudo dos especialistas nas wätunnä, que os Ye'kwana atuais são "todos misturados”. Seguia-se a esta afirmação a seguinte explicação: a língua que falam hoje está repleta de termos de outras línguas que eram faladas por gente com a qual "nos misturamos" ${ }^{7}$ - os Mawiisha ${ }^{8}$, povo canibal contra o qual guerrearam, apareciam como o exemplo por excelência. À medida que fui mergulhando no estudo das wätunnä, as narrativas sobre alguns destes Outros com os quais os Ye'kwana teriam se misturado foram me fornecendo pistas para entender melhor os sentidos implicados nesta "mistura".

Uma das narrativas de grande importância para os Ye'kwana é aquela que relata a demarcação do território tradicional por Kuyujani. Coube a Kuyujani, herói primordial enviado à Terra pelo demiurgo Wanaadi, a tarefa de demarcar o território ye'kwana. Kuyujani partiu de Kamasonha, local onde está a serra Ye'kwanajödö, de onde surgiram os primeiros ye'kwana. A narrativa que relata a odisseia de Kuyujani descreve os diversos lugares que demarcam o território ye'kwana e seus limites, onde Kuyujani encontrou outros povos, alguns deles, inimigos. Essa wätunnä narra ainda várias das doenças contraídas nos diversos locais pelos quais Kuyujani passou e o seu misterioso desaparecimento depois de retornar a Kamasonha. Dizem os Ye'kwana que ele entrou no monte Ye'kwanajödö com suas irmãs e retornará quando este ciclo de vida na Terra tiver fim, iniciando um novo ciclo. Não reprodu- 
zirei aqui a extensa narrativa, da qual coletei duas versões. Uma foi registrada em 2005, em Auaris, e me foi contada por Luís, um especialista em wätunnä da comunidade Adajameña (Rio Cuntinamo), do lado venezuelano da fronteira, e viveu por algum tempo em Fuduwaadunna, tendo sido um dos meus principais instrutores. A outra foi coletada em 2014, em Waichannha, de Vicente Castro, reconhecido como um dos maiores sábios ye'kwana ainda vivo. Ambas as versões têm conteúdo bastante similar, mas nomes de lugares por onde ele passou e de pessoas criadas por Kuyujani ou por seu arqui-inimigo Odo'sha aparecem mais detalhadamente na versão narrada por Vicente Castro. Mencionarei um trecho da narrativa que está diretamente ligado ao argumento desenvolvido aqui.

Kuyujani partiu de Kamasonhano e andou pelo mundo. Assim que ele começou a andar, Odo 'sha' mandou todas as doenças que assolam hoje osYe' kwana, para tentar matar Kuyujani - as enfermidades foram enviadas na forma de feitiços. De Kamasonha, ele partiu para Matacuninha. Aí, Odo’sha criou MakuWeichö. Kuyujani seguiu para Kiyakuninha. Aí Odo’sha criou Maku Weichö novamente. Kuyujani seguiu para o Rio Medewadi. Odo'sha criou aí um föwai [xamã], por isso até hoje existem muitos föwai nesta comunidade, Akudajadänha. Kuyujani seguiu para Kudutunnha. Aí, Odo'sha criou Kadi'nha Weichö [identificados pelos Ye'kwana como os atuais Kariña, que vivem na Venezuela] na margem esquerda e ShajeWeichö [atuais Xiriana] na margem direita. Por onde andou, Odo'sha criou pessoas para matar Kuyujani, mas Kuyujani convencia as pessoas: fiquem aqui, cuidem deste pedaço de Noono [a Terra]. Ele dizia: cuidem daqui, eu vou embora. Kuyujani dizia para estas pessoas que vivessem ali e cuidassem de Noono, para ajudá-lo. Ele sabia que haviam sido criadas para matá-lo, mas os convencia do contrário.

Em Tunamonnha, onde Kyuyjani construiu sua ätta [casa redonda ye'kwana], Odo’sha criou Ätti Weichö [Macuxi]. Ele os criou como onça. Depois, Kuyujani seguiu para Dimininnha [Demini, região onde hoje vivem os Yanomami]. Odo'sha criou aí MawadeWeichö, dentro da montanha. Ele criou Madichai, aquele que é o ancestral de Davi Kopenawa [xamã e líder yanomami que vive hoje no Demini]. Depois foi para Penamä, onde hoje é a cidade de Belo Horizonte. Odo'sha criou aí Maxacali Weichö [os Maxacali]. A partir daí, Kuyujani criou a divisão: a região das cabeceiras passou a ser dos povos indígenas e para o sul, dos brancos.

Kuyujani voltou para as cabeceiras, para Medewadinha. Em Kushiminnha, Odo'sha criou Waduwadu Weichö, em Täjuwadi criou Ajaja Weichö. Kuyujani seguiu para Entawadennha, onde hoje está a comunidade Anachännha. Kuyujani fez aí uma grande festa, onde surgiram as flautas wana ${ }^{10}$. Em Anachännha Odo'sha criou Iawadana Weichö e Fiadua Weichö [atuais Piaroa]. No mesmo rio, ele foi para Shiwomonnha. Odo'sha criou aí MakuWeichö novamente. 
Em Madakuanha, na foz do Rio Entawadi, por onde passou Kuyujani, Odo'sha criouWaniwa Weichö [atuais Baniwa] e Shajooko Weichö [atuais Tukano]. No Rio Orenoco, para onde seguiu Kuyujani, Odo’sha criou KudipakuWeichö [Curipaco], Shidishina Weichö [Sanumá], Wataiyakajamo Weichö e Kawedanuma Weichö. Kuyujani mudou-se então para Kununnha, nas cabeceiras. Odo'sha criou aí Mawiisha Weichö, que eram também como onças, tinham sete cabeças de onça e corpo humano. Eles comiam gente. Kuyujani seguiu então para o Rio Fadamo [Rio Padamo], onde Odo'sha criou Kudujashi Weichö, que eram parentes de Mawiisha e onças também. Assim como os Mawiisha, eles comiam osYe'kwana. Após criar Kudujashi, Odo'sha encerrou seu trabalho.

Após terminar a demarcação do território ye’kwana, Kuyujani voltou para Kamasonha, onde houve uma grande festa.

No relato da odisseia de Kuyujani, vimos surgir a criação de diversos povos por Odo'sha com o propósito de matar o herói. Potenciais inimigos foram transformados em aliados por Kuyujani na tarefa de cuidar da Terra. Diversas narrativas que coletei tratam mais especificamente de relações tanto de aliança quanto de guerras posteriores com vários dos povos criados por Odo'sha, revelando que o pacto primordial estabelecido por Kuyujani não estava imune a atualizações contextuais (voltarei a este ponto mais adiante). Quero me deter aqui sobre a tradução do termo weichö. Poderíamos traduzi-lo como "povo"? Além da evidente relação com o lugar de origem, com o território que lhes foi designado, que outros elementos são constitutivos de um weichö particular?

Ao perguntar a Vicente Castro o que constitui o Ye'kwana weichö, ele me respondeu: as wätunnä, narrativas de origem, os a'chudi e os ädemi, cantos ye'kwana. Narrativas e cantos constituem a fonte última do conhecimento ye'kwana, carregando o saber acerca do surgimento do mundo, dos seres, das relações entre eles, bem como as regras e valores que devem pautar a vida - em suma, a matriz relacional ye'kwana. Enquanto corpus de conhecimento, trata-se de um todo aberto à experiência e à incessante produção e incorporação de novos elementos oriundos da própria experiência mundana e da criatividade e interpretação dos sábios. Associados ao conceito de weichö, estão os termos iyeichö, que podemos traduzir como "regras", e weichoje, "modo de vida". Bernaldo, filho de Vicente e jovem com aguçada sagacidade para interpretar e traduzir as narrativas que ouvíamos seu pai contar, disse-me, quando conversávamos com Vicente sobre o conceito de weichö e weichoje: "É o que vocês, brancos, chamam de cultura. É o jeito ye'kwana, nosso modo de vida. São as coisas do espírito”. A língua também é arrolada como um dos elemen- 
tos constitutivos do weichö, e é bastante revelador um trecho da versão coletada, em 2005, da odisseia de Kuyujani, narrada por Luís:

Antigamente, falava-se apenas uma língua. Começou a festa em Anachännha. Kuyujani convidou todas as comunidades, todos os povos. Foram vários dias de festa, mais ou menos uma semana. As mulheres fizeram caxiri. Os inimigos de Kuyujani tinham pedrinha [widichi, pedras com poder xamânico], quando o pessoal fica bêbado não pensa, faz coisas erradas. Até hoje é assim, no mundo inteiro. Havia muita bebida. Havia música, mas não era música ye'kwana, era como a música dos brancos, que até hoje o pessoal escuta nas festas e não é boa para nós. Foi depois dessa festa e das brigas que ocorreram lá que cada um começou a falar sua própria língua, Fiadoa, Maku, Sidishina... como é até hoje.

Em 2009, quando conversava com um pequeno grupo de seis homens em Auaris sobre os diferentes modos de vida, Davi, atual chefe de Fuduwaaduinha, nos contou que "Wanaadi deu a cada povo um weichö e uma língua. Antes era uma só língua, mas depois que Wanaadi dançou em Anachännha, as várias línguas surgiram. Foi uma confusão, ninguém se entendia mais”. A diversidade linguística aparece cedo como uma marca das relações entre os diferentes weichö, iconizando a produção da diferença. A partir de sua instituição, ela figura como um dos elementos que passam a apontar para as trocas e a "mistura". Raimundo, um dos iynchonkomo ${ }^{11}$ de Fuduwaaduinha, disse-me que:

Os ye’kwana morreram todos, agora estão todos misturados. Ninguém mais fala a verdadeira língua ye’kwana, a língua está misturada com a língua mawiisha e tömomiyemö. Estes eram inimigos, nossos antepassados fizeram guerra contra eles e venceram. As crianças que sobraram casaram com ye'kwana e a língua ficou misturada, Ninguém mais sabe falar a língua ye'kwana pura, é muito difícil. Os ye'kwana são descendentes de Mawiisha, porque casaram com as moças e mulheres. Com os Maku foi a mesma coisa. Tinha muito Maku no Tucuxim [região onde hoje está a aldeia ye’kwana Kudataanha]. Eles eram guerreiros, valentes, inimigos dos ye'kwana. Agora não existe mais Maku eYe'kwana, só descendentes, porque casaram entre eles e se misturaram.

Ouvi de muitos iynchonkomo falas semelhantes à de Raimundo sobre a mistura com antigos inimigos, especialmente os Maku, Mawiisha e Tömomiyemö. A tônica da mistura é sempre a língua. "Ninguém fala mais a língua ye’kwana, que está misturada" é uma afirmação que escutei inúmeras vezes dos velhos. A mistura apontava sempre para elementos relacionados ao modo de vida, muito distante da concepção de matriz ocidental em que a "mistura" remete a aspectos biológicos-genéticos. E aqui, a mistura é algo de que não se pode - e nem se deve, arrisco dizer - escapar. 
Ela resulta não apenas da relação com inimigos, mas da própria incorporação criativa de elementos oriundos dos vários weichö originários. Somente os ye'kwana do passado, aqueles do tempo em que o atual ciclo de vida na Terra ainda estava se fazendo, puderam experimentar tal condição de "pureza" que aparece nas falas dos iynchonkomo. Da língua originária, dizem, restaram os cantos. ${ }^{12}$

Há uma série de wätunnä que narram as muitas guerras contra os inimigos do passado. O que há de comum a todas elas é a adoção das crianças e o casamento com as mulheres sobreviventes, dando lugar à mistura - que aparece sempre na forma de mistura linguística. O que resulta da mistura não é a perda da condição de ser ye'kwana, mas a transformação desta condição - do modo de vida ye'kwana. Há um outro aspecto das narrativas que merece ser aqui destacado: a própria condição de inimigo não era estanque. Na guerra contra Mawiisha, são os Maku que aparecem como aliados, como nesta versão narrada por Luís:

Mawiisha eram inimigos dos ye'kwana. Eles chamavam pessoas para trabalhar com eles, quando as pessoas descansavam, eles ficavam com raiva, mandavam a pessoa pegar água e lenha e depois cozinhavam a pessoa e comiam. Mawiisha comeu o pai deWadataduuma, que resolveu vingar-se. Ele foi chamar os Maku para ajudar. Estes Maku moravam acima deWaichanha [Waikás, onde hoje há uma comunidade ye'kwana], num lugar chamado Wademoinha.Wadataduuma foi buscar ajuda dos Maku, que estavam fazendo uma arma de madeira. Os Maku eram muito guerreiros, então eles gostaram do convite e aceitaram. Reuniram todos num só lugar, mataram um uru, cozinharam, dividiram em pequenos pedaços e comeram antes de ir para a guerra. Quem não comia do uru não podia ir à guerra.

Existe uma árvore cuja resina, quando queimada, ilumina como uma vela. Eles colocaram no cupinzeiro, fizeram lanternas e foram até Mawiisha. Esperaram anoitecer. Mawiisha estava levando ye’ kwana como prisioneiros, amarrados. O pessoal ficou lá fora esperando alguém [um dos cativos ye’kwana] sair para pegar água. Eles sabiam que ia sair alguém. Saiu um, eles foram falar com ele, perguntaram quantos ye’kwana já tinham morrido. Então avisaram, nós viemos buscar vocês, essa noite vai ter guerra. Mawiisha era muito esperto, tinha feito cerca alta, dois metros de altura, cercando toda a aldeia. O pessoal avisou: quando vocês escutarem o barulho da gente, vocês deitam no chão. Assim que a gente começar a matar Mawiisha, vocês deitam.

A cerca era muito alta e havia muita gente lá dentro. Os ye'kwana e os Maku foram arrodeando a cerca, tinha muita gente também. Era noite, chovia e trovejava, caíam raios. Mawiisha percebeu e cercaram também pelo lado de dentro. Mawiisha gritava:Wadataduuma está chegando, nós não temos medo!

Os ye'kwana jogaram os cupinzeiros acesos por cima da cerca, para iluminar.Wadataduuma 
entrou para brigar, os cativos ye'kwana deitaram no chão. O irmão mais novo de Wadataduuma, Iyaduumadi, e um Maku entraram também. Apenas os três entraram e mataram Mawiisha muito rápido. Os outros ficaram lá fora, quando alguém saía para fugir, o pessoal matava. Lutaram até acabar. Quando acabou a guerra contra Mawiisha, os sobreviventes casaram-se com Ye'kwana e se misturaram.

Em outra wätunnä, que me foi contada em Fuduwaaduinha pelo iynchomo Vitorino (que hoje vive em Kudatanha), é narrada a batalha contra os Maku, outrora aliados. Vitorino comentou brevemente, ao narrar a história, sobre a guerra contra Mawiisha e Tömomiyemö:

Mawiisha eram da família da onça, por isso comiam gente. Quando acabou a guerra contra Mawiisha, os que sobreviveram casaram-se com ye'kwana e se misturaram. Outros inimigos eram Tömomiyemö. Eles ficavam perto do Fiyakwannha [a aldeia ye’kwana do lado venezuelano da fronteira mais próxima de Fuduwaadunnha]. Eles também se misturaram com os ye'kwana mais tarde.

Töwadiyamö matou Makaadija, que era pajé. Makaadija mexeu com a mulher dele, por isso ele matou Makaadija. O irmão de Makaadija era Madaakuna. Os dois irmãos haviam feito armadilha para caçar. Eles caçavam juntos. Depois que Makaadija morreu, Madaakuna caçava sozinho. O urubu-rei tinha comido o corpo do irmão morto, e ao chegar ao céu, o irmão ressuscitou e ficou vivendo lá com os urubus-rei. Madaakuna continuou caçando com a armadilha que os dois tinham feito. Ele deixava a armadilha lá e quando voltava, só encontrava penas dentro da armadilha. Ele pensava, quem está comendo a caça? Madaakuna foi então de madrugada e ficou escondido, para ver quem estava roubando a caça; Ele ficou esperando. De repente, chegou Madaakuna, na forma de urubu-rei, e desceu até o chão. Ele tirou a roupa de urubu-rei e então Madaakuna viu que era o irmão morto. Ele foi até lá e disse, você está vivo! Eu pensei que você tinha morrido! O irmão respondeu, sim, estou vivo.

Makaadija morava na Venezuela, mas ele tinha vindo para o lado de cá, ele tinha casado com uma mulher Maku lá onde fica a pedra pintada [hoje Terra indígena São Marcos, terra Macuxi]. Ele perguntou ao irmão, o que aconteceu, o irmão respondeu, foi o pessoal Maku que me matou. Madaakuna disse, e agora, como é que faremos guerra? Existem armas lá no lugar onde vive o urubu-rei, você viu? O irmão respondeu, tem sim. Madaakuna disse, então eu vou lá contigo buscar. Makaadija vestiu a roupa de urubu-rei, mas não conseguiu levar o irmão junto. Ele disse então, espere um pouco, eu vou buscar outra roupa. Ele foi e voltou com a roupa para o irmão, que vestiu e eles foram juntos. Voaram acima das nuvens, lá onde não há vento, um lugar chamado sejianö. Eles voavam como os aviões, planando. Passaram por um lugar chamado cachoeira da mosca e atravessaram-na por cima. Passaram por outra cachoeira 
e chegaram ao lugar onde viviam os urubus-rei. Eles chegaram meio-dia e os urubus tinham ido pescar. $O$ irmão estava fedendo a suor, os urubus perguntaram, o que está fedendo? Os urubus foram chegando e se reunindo. Koshawaadi era o chefe dos urubus. $O$ irmão que estava fedendo estava escondido e foi olhar a reunião, viu muitas armas. Tinha espada grande de duas pontas, chamada sekekuyena. O chefe explicou a Makaadija, que pediu as armas para fazer guerra: tem arma.

Primeiro, o chefe decidiu fazer o casamento de Madaakuna. Mandou fazer festa, fazer bebida com caldo de milho. Madaakuna não quis fazer sexo com a mulher, ele sabia que se fizesse sexo com ela, nunca mais voltava para casa. Os urubus tinham saído para caçar e pescar para a festa e estavam voltando. Eles trouxeram muito berne. Os bernes começaram a andar pelo corpo de Madaakuna, ele ficou parado, sem se mexer. Ele sabia que se não aguentasse, iam mata-lo. A mulher veio, fumou e soprou no olho dele, os bernes viraram peixes. Eles começaram a beber a bebida feita de milho e o próprio Madaakuna distribuiu a bebida para os outros. Eles beberam a noite toda e ficaram bêbados, os urubus. A festa terminou. O chefe dos urubus mandou então Madaakuna secar a água de um lago. Ele começou a secar. Ele arranjou um pessoal para ajudá-lo. O lago secou. O chefe disse, muito bem, você trabalhou mesmo! Então o chefe mandou-o construir uma casa em cima da pedra. Ele pensou, como farei isso, não dá para cavar na pedra! A mulher dele ajudou-o a pensar. Chamaram a minhoca e ele mandou que ela cavasse para colocar as vigas da casa. A casa ficou pronta. O chefe mandou que ele fizesse então um banco com seis cabeças iguais às dele. O chefe ficava dentro de uma casa escura e Madaakuna não conseguia vê-lo. Ele se transformou então na aranha, teceu uma teia fina em cima do chefe e fez cocô nele. O chefe disse, tragam-me água. Trouxeram. Iluminaram a casa e então Madaakuna, na forma de aranha, viu o chefe, fez desenho da cabeça dele e foi embora. Assim ele fez o banco. Ele virou gente de novo e colocou um marimbondo debaixo do banco. Quando o marimbondo ferrou o chefe, Madaakuna fugiu. Foi assim que ele conseguiu se salvar. Ele sabia que o chefe queria matá-lo.

Madaakuna voltou para a terra dos Maku, em Kujakänha. Ele tinha levado a arma do urubu-rei e, chegando lá, fez uma casa redonda com uma janela no teto. Ele convidou os Maku para a festa, tinha muita bebida. Os Maku vieram, era muita gente. Os Maku sabiam que ele tinha trazido a espada e queriam ver. Alguns Maku foram embora com medo da espada, outros disseram, acho que é mentira, eu quero ver. Madaakuna pensou, quando acabar a festa, eu vou mostrar a arma a eles. Makaadija tinha explicado a ele, na hora da guerra, fique deitado no chão.

No fim da festa, ele mostrou a arma a todos. Os Maku foram passando a arma de mão em mão. Um Maku perguntou como se usava, foi experimentar e acabou matando um por um. Quando ele terminou, a arma sumiu.Todos os Maku morreram. Makaadija foi empilhando os 
corpos como se eles fossem mesas e bancos. Os urubus-rei vieram comer os mortos. Madaakuna ficou só olhando, ele não comeu. Vieram muitos urubus. A mulher dele e o chefe dos urubus vieram também. Eles comeram muita carne de Maku. Todos dançaram com a mulher- urubu de Madaakuna e pegaram piolho dela. Até hoje as pessoas pegam piolho. Eles cantaram: Makaadija comeu! Makaadija comeu! Assim é que venceram os Maku. ${ }^{13}$

Aliados na guerra contra Mawiisha, os aguerridos Maku também foram atacados pelos ye'kwana, com o propósito de vingar uma morte. Com eles, havia-se celebrado inclusive, antes da guerra, uma aliança, através do casamento de Makaadija, que viria a ser morto, e uma mulher maku. Aqui, os aliados incidentais são os urubus-rei, que celebram um banquete com os cadáveres dos Maku mortos com sua arma. Tal aliança não deixa de ser eivada de perigo. Percebemos aqui a produção de um gradiente de proximidade e distância em que os Outros são alocados, ao sabor do contexto. Tais características do modelo ye'kwana de relação com a alteridade aparecem também em contextos mais recentes como os examinados por Arvelo-Jiménez, pioneira na análise dessas relações interétnicas, que denominou a rede de aliados na qual estavam inseridos os ye'kwana de SIRO, Sistema Regional de Interdependencia del Orinoco, e afirmou que ela marcava um sistema de interdependência que alternava ações cooperativas não só de luta face a um inimigo comum, mas trocas materiais, matrimoniais e religiosas, com ações bélicas de baixo impacto para o restabelecimento de limites e fronteiras diacríticas que evitavam a ruptura da rede (2001). Com a chegada dos colonizadores, essa rede sofreu grande revés, sobretudo com a dispersão e fuga de muitos povos diante do temor da escravização. Entretanto, os Ye'kwana seguiam fazendo comércio, seja com os parceiros que lhes restavam, seja com novos parceiros, dentre os quais os próprios colonizadores, demonstrando que a necessidade de trocar se sobrepunha a qualquer adversidade, pois, através das trocas, era possível a obtenção do conhecimento que estava em mãos estrangeiras.

Arvelo-Jiménez mostra que o SIRO funciona congregando diversos povos indígenas numa aliança que emerge em situações liminares, como guerras, seja num passado remoto, como atesta wätunnä, seja num passado muito próximo, como foi o caso da invasão das terras ye'kwana na Venezuela nos anos 1970. Em 1971, por ocasião da invasão de suas terras por fazendeiros venezuelanos, os Ye'kwana, através de um representante em Caracas, publicaram em um dos jornais de maior circulação do país uma nota denunciando a invasão e convocando o governo a tomar uma posição, caso contrário, estavam dispostos a entrar em guerra contra os invasores. Ao mesmo tempo, um representante da etnia Guajiro informava ainda que 
todas as suas aldeias estavam prontas a oferecer apoio aos Ye'kwana. Tal fato era, até então, inédito na Venezuela e desencadeou uma série de eventos que mudariam o movimento etnopolítico venezuelano. Seguiu-se na imprensa um debate entre os partidários dos invasores, que alegavam tratar-se aquela terra de tierra baldía, terra devoluta, inabitada, e os partidários dos Ye'kwana (e estes próprios) de que, apesar de aquela porção do território não ser habitada naquele momento, tratava-se de reserva de caça e pesca, vital para a sobrevivência do grupo. O ministro da justiça venezuelano foi convocado pelo congresso a se pronunciar após denúncia encaminhada por uma delegação de antropólogos. Por fim, o Instituto Agrário Nacional retirou os invasores e incorporou a área novamente à sua jurisdição (Coppens, 1971, 1979; Arvelo-Jiménez, 2001). Embora tenha existido a articulação de instituições e antropólogos, destaca-se aqui a atuação dos próprios Ye'kwana, deflagrando as denúncias, e o papel decisivo de outros indígenas que se manifestaram em apoio, mostrando a rede de solidariedade ye'kwana conquistada, sobretudo, através da rede de trocas. Com esse episódio, os Ye'kwana inauguraram na Venezuela um novo modo de diálogo entre a sociedade nacional e os indígenas, que perceberam na imprensa um veículo importante para defender seus direitos. Ao longo de sua história, os Ye'kwana formaram uma rede de relações comerciais que, como nos aponta Arvelo-Jiménez (2001, 2014; Arvelo-Jiménez et al., 1981, 1989), emerge como uma cadeia de alianças em momentos decisivos. Dentre as diferentes unidades constitutivas de tal rede, o jogo de proximidade e distância pareceu operar tendo em vista os princípios norteadores da maneira como a matriz relacional ye'kwana se debruça sobre a diferença. A proximidade dá lugar a trocas e à incorporação de elementos que imprimem dinâmica à constituição de uma socialidade singular que não suprime a diferença no seu interior.

Alternativamente ao que proponho aqui, de que o que está em jogo na produção da "ye'kwanidade" é o compartilhamento de um mesmo weichö, a tese de Monterrey, como já mencionado, é que a unidade identitária ye'kwana é fruto de um longo processo de síntese populacional e cultural, que se deu a partir da incorporação de outros grupos étnicos, alguns deles identificados pela autora através de um levantamento inédito, a partir de fontes bibliográficas e de sua própria etnografia. Monterrey sustenta que três destes grupos permanecem operando como subgrupos no interior da unidade étnica ye'kwana, com famílias de remanescentes identificados como descendentes dos mesmos. Estes três subgrupos, Mawiisha, Tümömiyemö e Ye'kwana, continuam operando no presente, mas são secretos e somente conhe- 
cidos de pessoas mais velhas e grandes sábios. Haveria, por parte dos velhos, um esforço de "esquecê-los", não falando deles. Segundo a autora, os jovens desconhecem a existência dos "grupos de filiação" (sic). Segundo os sábios, eles remeteriam a coisas do passado que devem ser esquecidas, pois poderiam provocar brigas e cisões. Até mesmo as narrativas de origem que falam sobre tais grupos permaneceriam guardadas em segredo. Monterrey interpreta tal fato como uma decisão estratégica de apresentar-se aos não-indígenas (e também aos outros indígenas) como uma totalidade coesa, sob o etnônimo Ye'kwana.

Apesar de mantido em segredo, o pertencimento a um dos subgrupos continuaria operando sobretudo no que se refere ao acesso aos cargos de chefia, bem como conferiria certo prestígio, embora tal pertencimento não esteja ligado a um conjunto de direitos e deveres específicos. Haveria, portanto, uma categoria englobanteYe'kwana e três subgrupos de filiação, um dos quais duplica o nome da categoria étnica abrangente. Tais subgrupos teriam sido alguns dos muitos grupos étnicos incorporados no passado e que por razões desconhecidas teriam permanecido como operadores no interior da “estrutura social ye'kwana”. Haveria, ainda, certa hierarquia no pertencimento a um destes grupos: Os Ye'kwana-Ye'kwana seriam considerados os "mais ye'kwana dentre os ye'kwana”, seguidos pelos Ye'kwana-Mawiisha, que tradicionalmente manteriam os cargos políticos, e por fim os Ye'kwana-Tümömiyemö. Certos valores morais estariam associados aos subgrupos, de acordo com um dos interlocutores da autora: “Mawiisha e Ye'kwana são como irmãos, um mau e outro bom”. Os Ye'kwana-Mawiisha são considerados bravos, dominantes e agressivos e os Ye'kwanaTümömiyemö, dóceis e submissos. Embora o poder político venha sendo mantido tradicionalmente nas mãos dos Ye'kwana-Mawiisha na região do Caura-Erebato, onde Monterrey concentrou sua pesquisa, mais recentemente algumas situações novas têm ocorrido, sobretudo diante do desconhecimento dos jovens a respeito do pertencimento aos grupos de filiação, como o caso mencionado por ela da eleição de um jovem ye'kwana-tümömiyemö para o cargo de coordenação numa organização intercomunitária. O pai deste jovem, surpreendido ao saber da eleição do filho e diante do desconhecimento do mesmo, revelou-lhe a existência dos grupos.

Além da diversidade constitutiva do grupo étnico, a autora traz dados relativos aos grupos dialetais. A partir de uma releitura dos dados de Koch-Grünberg, que apontou a existência de quatro dialetos da língua ye'kwana, a saber: yekuana, Ihuduana, Dhe'kuana e Kunuhana, a autora afirma que hoje há variação dialetal entre os De'kwana e os Ye'kwana, que se percebem como o mesmo grupo étnico. Para 
muitos velhos, o de'kwana é a fala culta dos ye'kwana. Muitos dos termos usados por Koch-Grünberg para designar diferentes dialetos são, na realidade, locativos (Arvelo-Jiménez (1974) discordara anteriormente da divisão do autor). Segundo Monterrey, os dois grupos dialetais, ainda que partes de uma mesma sociedade, também seriam indicativos de uma diversidade constitutiva que, embora não mais ativa, seja provavelmente similar às divisões clânicas, ${ }^{14}$ considerada a tradução livre de cada um dos termos ('gente do cachorro de água' para Kunuhana e 'gente do golfinho’ para Ihuduana). Com relação aos subgrupos originários, Tümömiyemö e Mawiisha, estes não estariam associados a um dialeto específico, tampouco a diferenças no comportamento cultural. Sobrepõem-se ao grupo de filiação o dialeto e o comportamento associados à aldeia em que se vive. Os grupos dialetais estão distribuídos em partes do território ye'kwana, formando quatro categorias de grupos dialeto-regionais: Merewari (com mescla dos dialetos); Erebato-Alto Ventuari (dialeto ye'kwana); Cunucunuma-Chajudaña (dialeto De'kwana) e Alto Caura-Baixo Paragua (mescla de dialetos). Monterrey apresenta os blocos dialeto-regionais como categoria analítica que articula os dois níveis de diferenciação no interior do grupo étnico ye'kwana: a variabilidade étnica constitutiva (os subgrupos) e a intensificação das relações sociais dada pela proximidade geográfica (formando redes de relações locais).

Monterrey, por fim, aponta ainda para certos mecanismos que operariam de modo a articular a produção de uma "sociedade diversa que constitui uma unidade social discreta, homogênea e integrada" (a comunicação e viagens entre as aldeias, através da realização de festas, rituais e torneios esportivos, mas, sobretudo, o xamanismo, caracterizado aqui como instituição política multicentralizada). O potencial advindo de reunir-se e transcender o nível do grupo local para assuntos que afetam a todos é uma das características que distinguem, segundo a autora, os Ye'kwana de outros povos indígenas da região, como o trabalho pioneiro de Arvelo-Jiménez (2001, 2014) já nos havia mostrado.

Gostaria de oferecer aqui uma alternativa aos conceitos mobilizados pela autora para pensar a constituição do mundo ye'kwana e como se articula nele a diferença. Como já aventado, tanto o conceito de grupo étnico quanto o de identidade étnica (além do próprio conceito de sociedade - voltarei a este ponto) parecem-me tímidos para traduzir da maneira mais acurada possível certo "idioma da mistura" acionado pelos Ye'kwana. Se, para Monterrey, "reconhece-se aqui a definição de [Frederik] Barth do conceito de grupo étnico: comunidade que se perpetua biologi- 
camente, compartilha valores fundamentais e integra um campo de comunicação e interação", a meu ver, mais do que a produção (e projeção) de uma identidade (que nos leva de volta ao campo da representação), cujos limites estão dados por uma unidade sociológica circunscrita em termos daquilo que convencionamos chamar de etnia, temos aqui a produção de uma socialidade particular, de um modo de fabricar corpos, pessoas e relações - e como a diferença é articulada nesta produção.

Estas ideias encontram ressonância no conceito ye'kwana de weichö, traduzido aqui como "modo de vida", que aparece na filosofia ye'kwana como elemento capaz de explicitar a diferença "nós” e os “outros" e me parece central para resolvermos certos (aparentes) paradoxos abordados na literatura etnográfica sobre eles. Assim como nas relações com seus Outros, cuja diferença é epitomada num modo de vida (weichö) distinto, também entre os que compartilham um mesmo weichö opera um gradiente de proximidade e distância que se inflete sobre as relações políticas. Isso se torna aparente quando tomamos em consideração o contexto atual das relações entre diferentes comunidades ye'kwana distribuídas ao longo do território outrora demarcado por Kuyujani e hoje cortado por uma fronteira internacional.

\section{Alianças e mobilidade em contexto binacional}

As relações entre os próprios Ye'kwana ganharam novos contornos com a dispersão pós-contato. A tradição oral ye'kwana nos diz que, no passado, todos os ye'kwana viviam no coração do território tradicional, nas cabeceiras dos rios que formam a bacia do Orenoco. Com a chegada dos colonizadores, a dispersão ganhou fôlego com investidas como a invasão caucheira e a busca de mão-de-obra escrava para o trabalho nos seringais, no século XVIII. Apesar da dispersão, os elos que unem as comunidades ye'kwana não foram quebrados. Com uma mesma língua e um conjunto de narrativas histórico-cosmológicas, os Ye'kwana continuaram partilhando um mesmo modo de vida. Isso não impediu, todavia, que algumas diferenciações operassem entre as comunidades agora espalhadas por um território consideravelmente amplo, hoje cortado por uma fronteira internacional.

Em linhas gerais, as comunidades que permaneceram nas cabeceiras veem a si mesmas como seguidoras do verdadeiro modo de vida tradicional e as demais, especialmente aquelas mais próximas das cidades, como mais “misturadas". Por sua vez, as comunidades que desceram o rio consideram-se abertas às mudanças, mas sem perder seu modo de vida, ao contrário do que pensam seus parentes das cabeceiras, que resistiriam às mudanças trazidas por uma nova realidade com a qual é preciso 
saber lidar. As comunidades das cabeceiras tentam preservar seu modo de vida tradicional evitando o contato muito próximo com os brancos. A região onde se situam as comunidades ye'kwana do lado brasileiro são consideradas como tradicionalistas, gente das cabeceiras que procura manter um modo de vida próximo aos ensinamentos e às regras (iyeichö) contidas nas narrativas wätunnä e nos cantos ädemi e a'chudi.

As relações entre as diferentes comunidades situadas em território brasileiro e venezuelano são marcadas por tal distinção, fazendo com que algumas delas mantenham relações de maior proximidade entre si, o que dá lugar a uma maior mobilidade de pessoas entre certas comunidades mais do que em outras, inclusive mobilidades oriundas de alianças matrimoniais. No caso das aldeias em que tenho trabalhado, do lado brasileiro, o relativo controle que se tem sobre o quanto de proximidade com o mundo dos brancos se deseja é favorecido inclusive pela própria geografia, que dificulta o acesso não-indígena à região. Somente na última década, após a criação de uma associação que representa o povo ye'kwana do lado brasileiro, cuja sede se localiza em Boa Vista, uma maior participação destes no cenário da política indígena regional tem ocorrido. Embora as relações comerciais com os brancos sejam de longa data e tenham se fortalecido também através da educação escolar, uma iniciativa que foi fruto dos esforços dos próprios ye'kwana (Andrade, 2012, 2014), esta tem sido uma proximidade controlada. Há uma demanda constante pela presença do Estado na forma de atendimento de saúde e da garantia dos direitos territoriais, mas sem interferência no seu modo de vida. Neste contexto, as relações com outras comunidades, situadas do lado venezuelano da fronteira, mantêm-se forte ainda que menos infletidas por se tratarem de "aldeias do lado brasileiro" ou "aldeias do lado venezuelano" e mais pela proximidade oriunda de certos valores compartilhados acerca de um modo de vida visto como mais ou menos tradicionalista. Diante do cenário de crise política na Venezuela, que também gerou ondas de imigrantes não-indígenas que cruzaram a fronteira em direção ao Brasil, famílias ye'kwana que viviam em comunidades do lado venezuelano migraram para as aldeias do lado brasileiro com a esperança de encontrar um contexto em que possam viver de acordo com os princípios que regem seu modo de vida, asseguradas as garantias à saúde e ao seu território, independentemente de em que lado da fronteira se está. Algumas destas famílias costumavam passar temporadas visitando seus parentes nas comunidades do lado brasileiro e diante do cenário de crise, optaram por estabelecer residência nelas por tempo indefinido. Há um caso de uma aldeia do lado venezuelano que mantém relações de grande proximidade com Fuduwaa- 
duinha e cuja população mudou-se na sua totalidade para esta comunidade, constituindo-se um processo de fusão de aldeias. Embora eventos tais como torneios de futebol de times de comunidades situadas em distintos lados da fronteira se enfrentem, exibindo camisas das seleções brasileira e venezuelana durante os jogos, prevalece sobre o estado-nação a força de um modo de vida compartilhado. Como me disse certa vez um jovem ye'kwana, hoje presidente da associação: fronteira é coisa de branco. Isso não significa absolutamente um desejo por reconhecimento de um Estado independente ye'kwana, uma vez que sua estrutura política passa ao largo da formação de tipo estado-nacional, mas simplesmente o desejo de manter seu território tradicional e seu modo de vida, como bem apontou Monterrey (2015).

O sentimento de pertença que partilham os ye'kwana, fazendo-os reconhecer-se como parte de um mesmo mundo, está vinculado ao fato de que comungam de um mesmo modo de vida, uma mesma socialidade, num universo pontilhado por uma miríade de outros modos de vida singulares. Tal sentimento se sobrepõe às identidades nacionais, embora aqui também o jogo da diferença/semelhança seja contextual tanto quanto nas relações com os seus Outros. Não se trata aqui de celebrar uma visão monolítica de um mundo particular, negando sua diversidade constitutiva (e originária), e menos ainda negar a possibilidade de que outras incorporações criativas de elementos estrangeiros continuem acontecendo, submetidas a uma lógica da transformação. Tal incorporação, por outro lado, não dá lugar a um trabalho de amalgamento das diferenças de modo a produzir um todo liso e homogêneo. Trata-se bem mais de uma maneira de produzir conexões a partir de um modo de vida compartilhado, este tampouco destituído de caráter dinâmico, dada sua plasticidade e abertura para o novo. Os conceitos de "grupo", "povo" e mesmo de "sociedade", cujas definições estão de uma tal maneira imbuídas de sentidos e significados profundamente atrelados à lógica de organização sócio-política típica de formações do tipo estado-nação, parecem aqui inadequados para traduzir o mundo ye'kwana.

\section{Agradecimentos}

Agradeço ao Conselho Nacional de Desenvolvimento Científico e Tecnológico (CNPq) pelo financiamento do projeto Povos indígenas, fronteiras e políticas nacionais (Processo 474964/2012-4), contemplado em Edital Universal. Agradeço à coordenadora do projeto, Alcida Rita Ramos, pelo apoio, estímulo e pela leitura da primeira versão deste artigo e sugestões feitas, em que pese ser o resultado final de minha inteira responsabilidade. 
Recebido: 05/10/2018

Aprovado: 21/10/2018

Karenina Vieira Andrade é doutora em Antropologia Social pela Universidade de Brasília (UnB) e atualmente é professora do Departamento de Antropologia e Arqueologia da Universidade Federal de Minas Gerais (UFMG). Desenvolve pesquisa etnográfica nas comunidades ye'kwana situadas no estado de Roraima, Brasil. Tem interesse nos temas de redes de comércio indígenas, sociocosmologias, sistemas de conhecimento e educação indígena. Nos últimos anos, além de pesquisadora, tem atuado como colaboradora na produção de material didático na língua ye'kwana junto aos professores ye'kwana no âmbito do programa Saberes Indígenas na Escola, financiado pelo Ministério da Educação, Unidade e diferença: os Ye'kwana e suas relações com a fronteira binacional. Contato: andrade.karenina@, gmail.com

\section{Notas}

1. Remeto o leitor ao texto de Wagner (2010), em que estão bem sistematizadas algumas das questões apenas mencionadas aqui.

2. Uso tanto o termo ameríndio quanto o termo ocidental aqui entre aspas de modo a indicar o valor mais heurístico (no sentido de pôr em destaque certas diferenças pelo contraste) e menos etnográfico que carregam. Trata-se de generalizações com as quais operamos e que, por se tratarem precisamente de generalizações, devem ser manejadas como tais, com as limitações que este uso implica. Se há em parte da literatura etnográfica certo constrangimento (ou cuidado) em falar de "mundo ocidental" como um todo homogêneo, muitas vezes esse mesmo constrangimento (ou cuidado) parece não se estender ao uso do termo "mundo ameríndio".

3. Ao longo do texto, quero problematizar o uso do termo unidade neste contexto. Permaneçamos com ele por ora.

4. Não me alongarei nessa discussão, tampouco farei aqui uma revisão da literatura acerca deste ponto. Remeto o leitor, para algumas referências e desdobramentos deste debate, a Taylor, 1986; Erikson, 2004, 2002 e 2011; Grupioni, 2011.

5. Lembremos, aqui, da clássica etnografia nuer produzida por Evans-Pritchard na década de 1940, que nos apresenta um mundo caracterizado por uma estrutura segmentar seja com relação ao 
sistema político-territorial, seja com relação ao sistema de linhagens. Entre os Nuer, os segmentos adjacentes (fossem eles linhagens menores ou mínimas, em lugar de linhagens maiores ou clãs, fossem eles seções terciárias ou aldeias, em lugar de tribos) emergiam como estruturas de sentido quando diante de segmentos de mesma monta, a depender do contexto em que se davam as relações. Guardadas, é claro, as devidas proporções, uma vez que Evans-Pritchard se referia àquela dimensão que convencionamos chamar de “organização social”, numa perspectiva centrada no funcionamento de instituições e de uma certa 'concretude da vida'. Aqui, embora na última parte do texto eu me volte para as relações políticas reais, iniciarei minha reflexão debruçando-me sobre princípios epistemológicos que operam na produção do que venho chamando até aqui de mundo ye'kwana (e que abarca, como dito, as relações com outros mundos).

6. As wätunnä são narrativas orais transmitidas de geração a geração e há diversos níveis de conhecimento que se pode atingir. Todo indivíduo ye'kwana, homem ou mulher, conhece, em alguma medida, ao menos as principais histórias wätunnä, aquelas sobre os temas mais debatidos, como o surgimento do mundo e dos seres que nele habitam. O processo de aprendizagem das wätunnä, que dura toda a vida, poderá transformar o estudioso num especialista a quem se recorre sempre que é necessário e que fica responsável pelo treino de estudantes da nova geração. O conteúdo das narrativas está intimamente associado aos cantos ädemi e a'chudi, os primeiros cantados em eventos rituais (tais como o festival de roça nova ou a construção e inauguração de uma casa) e os segundos estão vinculados a processos de cura de doenças ou de cuidados corporais tais como o nascimento de uma criança (e as muitas etapas decorrentes: a primeira saída de casa do bebê e sua mãe, o primeiro banho, a primeira vez que cada alimento é consumido) e a primeira menstruação. 7. Gongora (2017) também relata que em sua pesquisa em Auaris, seus interlocutores ye'kwana se referiam à mistura como relativa à língua falada hoje.

8. Na pesquisa com os Ye'kwana que vivem nas aldeias situadas do lado brasileiro, os Mawiisha não são identificados com nenhum grupo atual. Diz-se apenas que os Ye'kwana de hoje estão misturados com os Mawiisha, mas não são identificadas aldeias ou famílias ye'kwana que seriam descendentes deles.

9. Arqui-inimigo do demiurgo Wanaadi, nascido de sua placenta apodrecida.

10. Flautas ye'kwana confeccionadas a partir de um tipo de bambu.

11. Iynchomo(sing.)/Iynchonkomo (plural) é o termo usado para se referir aos velhos, cujas palavras são de grande peso. Temos aqui um conceito de autoridade (no sentido que lhe confere Gadamer e que advém de autoria) que emana da experiência e da sabedoria de quem muito viveu e acumulou conhecimento.

12. Dizem os ye'kwana que a fala dos cantos é de difícil compreensão, pois as palavras que nomeiam seres e coisas não são as da língua corrente. Somente os grandes sábios, especialistas nos cantos e nas narrativas, conhecem seu significado.

13. Há muitas camadas de significado nesta narrativa que não serão aqui analisadas. Por exemplo, comensalidade como marca da diferença entre os seres, tornando o compartilhamento de alimento algo perigoso, uma vez que este é elemento central na produção de corpos (e consequentemente de pessoas) de certo tipo (o berne dos urubus, seus peixes), bem como o compartilhamento de fluidos corporais (a recusa de sexo com a mulher urubu-rei, que daria lugar a uma transformação perigosa, impedindo Madaakuna de voltar para casa, ou ainda o perigo da aliança com gente-Ou- 
tra, encarnado no sogro que imputa ao genro tarefas impossíveis, com o objetivo de vê-lo falhar e então matá-lo. As narrativas condensam múltiplos conhecimentos que o saber científico compartimentaliza. Numa única história, podemos ver narração de feitos do passado, conhecimentos escatológicos, filosóficos, astronômicos, botânicos...

14. Do lado brasileiro, não encontrei traços de unilinearidade com os quais se possa traçar uma analogia com as divisões clânicas.

\section{Referências bibliográficas}

ANDRADE, K. V. 2007. A Ética Ye'kuana e o Espírito do Empreendimento.

Tese de Doutorado, PPGAS/UnB.

ANDRADE, K.V. 2010. "Construindo lugares, transformando pessoas. A dialética do espaço entre os Ye'kuana”. In:TRAJANO FILHO, Wilson. (Org.). Lugares, Pessoas e Grupos: as lógicas do pertencimento em perspectiva internacional. Brasília: Athalaia.

ANDRADE, K. V. 2011. “Jogando com espelhos: os Ye'kuana e seus outros”. In: COFFACI DE LIMA, E. \& CÓRDOBA, L. (orgs). Os Outros dos Outros: Relações de alteridade na Etnologia Sul-Americana. Curitiba: Editora UFPR.

ANDRADE, K. V. 2012 A vontade de saber - a escola e o mundo das profissões entre os Ye'kuana. Revista Brasileira do Caribe (Impresso), v. XIII, p. 43-71.

ANDRADE, K. V. 2013. Alteridades (in)corporadas: notas sobre a chefia Ye'kuana. Anuário Antropológico, v. 2012/I, p. 59-82.

ANDRADE, K.V. 2014. Acumulando saberes - o processo de escolarização no contexto ye'kuana. Teoria \& Sociedade (UFMG), v. Especial, p. 202-218.

ARVELO-JIMÉNEZ, N. 1974. Relaciones políticas em uma sociedad tribal. México:Instituto Indigenista Interamericano.

1990. IndigenismoY debate sobre desarollo amazónico. Reflexiones a partir de la experiencia venezolana. Série Antropologia 106. Departamento de Antropologia, Universidade de Brasília.

2001. “Perspectivas y lecciones”. In Simeón Jiménez e Nelly Arvelo-Jiménez (orgs.), Atlas Dekuana. Caracas: Asociación Kuyujani Originário y Asociación Outro Futuro.

2014. Movimientos etnopolíticos contemporáneos y sus raíces organizacionales en el sistema de interdependencia regional del Orinoco. Anuário Antropológico 2014/II: 133-160.

ARVELO-JIMÉNEZ, N. \& MORALES MÉNDEZ, F., 1981. Hacia un modelo de estructura social caribe. América Indígena XLI (4): 603-626.

ARVELO-JIMÉNEZ, N., MORALES MÉNDEZ, F., \& CASTILLO, H. B. 1989. Repensando la historia del Orinoco. Revista de Antropología 5(1-2): 155-173.

BARANDIARÁN, D. de. 1981. Introducción a la cosmovisión de los Índios Ye’kuana-Makiritare. Caracas: Universidad Católica Andrés Bello, Instituto de Investigaciones Históricas, Centro de Lenguas Indígenas.

COPPENS, W. 1971. Las relaciones comerciales de los Yekuana del Caura-Paragua. Antropologica 30: 28-59. 
.1979. The anatomy of a land invasion scheme in Yekuana territory, Venezuela. Copenhaguen: IWGIA Document 09.

ERIKSON, P. 2011. "Prólogo”. In. Coffaci de Lima, E. \& Córdoba, L. (orgs). Os Outros dos Outros: Relações de alteridade na Etnologia Sul-Americana. Curitiba: Editora UFPR.

EVANS-PRITCHARD, E. E. 1993 [1940]. Os Nuer. São Paulo: Perspectiva.

GADAMER, H-G. 2008. Verdade e Método I, Traços fundamentais de uma hermenêutica filosófica. Petrópolis: Vozes.

GOODY, J., 2008. O roubo da história. São Paulo: Contexto.

GONGORA, M. F. 2017. Ääma ashichaato, replicações, transformações, pessoas e cantos entre os Ye'kwana do Rio Auaris. Tese de Doutorado, PPGAS/USP.

GUSS, D. 1990. To Weave and Sing - Art, Symbol and Narrative in the South American Rain Forest. Berkeley: University of California Press.

LEACH, E. 1995 [1954]. Sistemas Políticos da Alta Birmânia. São Paulo: Edusp.

LÉVI-STRAUSS, C. 1993. História de lince. São Paulo: Companhia das Letras.

RAMOS, A. R. (org.). 1980. Hierarquia e simbiose. Relações intertribais no Brasil. São Paulo: Hucitec.

SILVA M, N. R. 2015. Poder, Parentesco y sociedade entre los Ye'kwana del Caura-Venezuela. Quito: Abya-Yala. 
Resumo: Neste artigo reflito sobre a constituição de uma unidade sociológica ye'kwana e da consequente matriz de relação destes com seus Outros, à luz do conceito nativo de weichö, que traduzo aqui como "modo de vida". O exame de como o "modo de vida" ye'kwana se constitui e opera é fundamental para se compreender a relação que estes estabelecem com a fronteira internacional que corta seu território tradicional, bem como as relações entre as comunidades ye'kwana situadas em território brasileiro e venezuelano.

Palavras-chave: Ye'kwana, fronteiras internacionais, alteridade.
Abstract: I focus on the formation of a Ye'kwana sociological unit and the matrix resulting from the relationships they establish with their Others, in light of the native concept of weichö ("way of life"). This concept is crucial to understand how the Ye'kwana relate to the international boundary, which cuts through their traditional territory, and to the Ye'kwana communities on both sides of the Brazil-Venezuela border.

Keywords: Ye'kwana, international borders, alterity. 